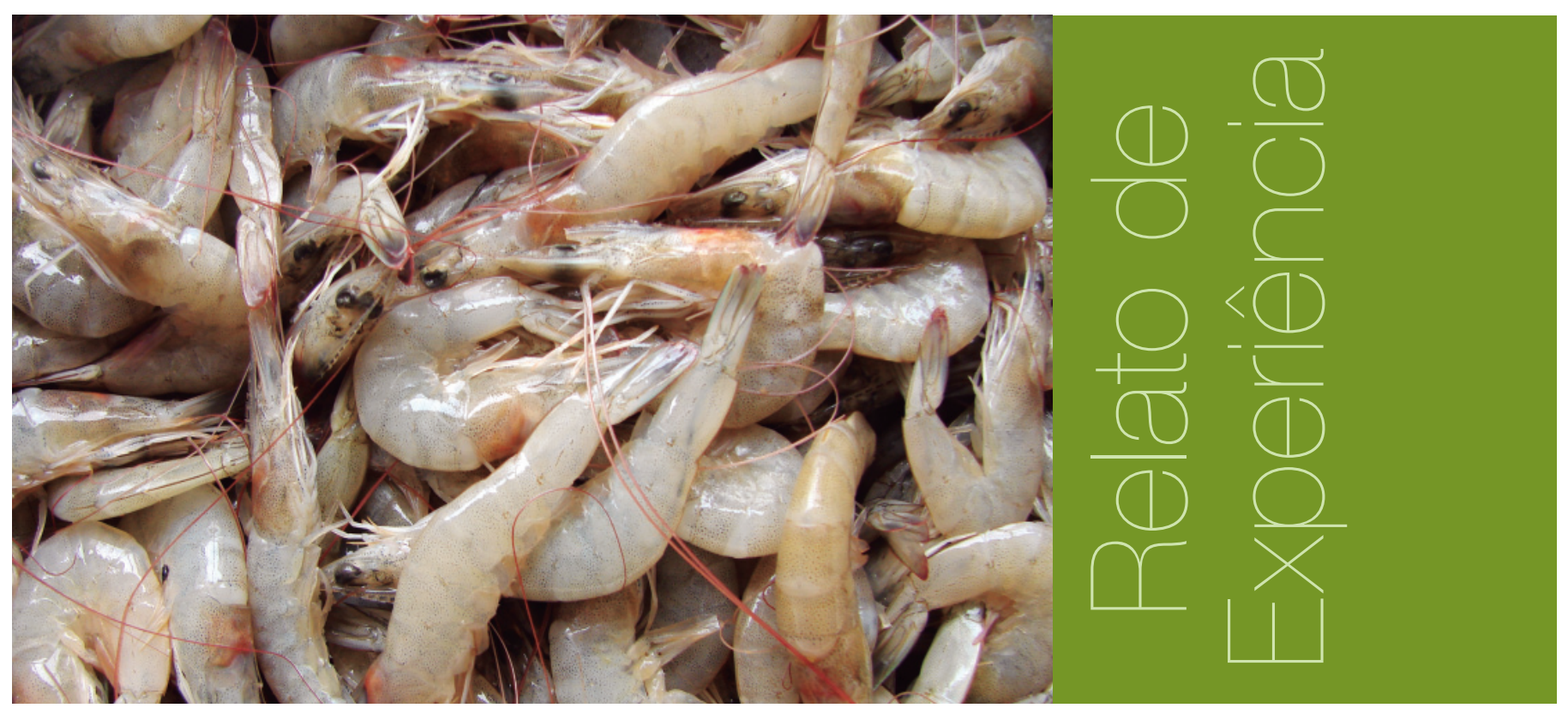

\title{
Carcinicultura: Relato de experiência no oeste do Paraná
}

\author{
Fabrício Martins Dutra1 - fabricio.m.dutra@gmail.com \\ Claudia Caramelo Brazão² - claudiacaramelob@gmail.com \\ Ademir Heldt ${ }^{3}$ - bio_miro@yahoo.com.br \\ Eduardo Luis Cupertino Ballester - elcballester@yahoo.com.br
}

\section{RESUMO}

0 objetivo do projeto é estimular a produção de camarões através do repasse de tecnologia e acompanhamento da produção pela equipe do Laboratório de Carcinicultura da UFPR - Setor Palotina. Anualmente, é ministrado um curso de extensão teórico/prático, onde é fornecido material didático. Os resultados vem demonstraram a viabilidade da produção em sistemas de monocultivo e policultivo, com índices de produtividade de acordo com os melhores resultados alcançados na atividade.

\section{PALAVRAS-CHAVE}

Aquicultura. Extensão. Produção. Camarão.

\section{ABSTRACT}

The Project purpose is to stimulate prawn production by the dissemination of techniques and guidance throughout the production cycle by the team of the Prawn Culture Laboratory of UFPR - Sector Palotina. Every year a capacitation course has been offer and didactic material has been distribute to share information about prawn rearing. Results achieved have demonstrate de viability of the system according to the best results reported in this activity.

\section{KEYWORDS}

Aquaculture. Extension. Production. Prawn.

\footnotetext{
1 Pós graduando no Programa de Pós Graduação em Zoologia, pela Universidade Federal do Paraná

2 Graduanda em Biotecnologia, pela Universidade Federal do Paraná-Setor Palotina.

3 Técnico da Universidade Federal do Paraná-Setor Palotina, Departamento de Zootecnia

4 Prof. Dr. da Universidade Federal do Paraná-Setor Palotina, Departamento de Zootecnia
} 


\section{Contexto}

A aquicultura é o setor de produção animal que mais cresce atualmente no mundo (FA0, 2014). Em 2011 o Brasil produziu 544 mil toneladas de pescado, tendo, na região sul a maior produção, com 153 mil toneladas, e o Paraná com a produção de 73 mil toneladas (MPA, 2013), com a maioria produzida por agricultores familiares.

Entre as atividades de aquicultura, a carcinicultura, ou criação de camarões, apresentam importância comercial por ser um produto nobre e de alto valor, com centenas de toneladas de camarão sendo exportado por ano (PÉREZ-RAMIREZ, 2010), tornando esse recurso, em termos de valor, a mais importante commodity pesqueira comercializada internacionalmente, com o mercado concentrado nos Estados Unidos, Japão e Europa (FA0, 2009). Atualmente, aproximadamente $50 \%$ dos camarões consumidos no mundo vêm de criação em cativeiro, 0 que corresponde em torno de 4,5 milhões de toneladas (FA0, 2012).

Atualmente, as maiores dificuldades encontradas para o desenvolvimento da carcinicultura de água doce em nosso país, está relacionada com a falta de disponibilidade de pós-larvas (PLs) e juvenis, que é produzida de maneira regular. Outra dificuldade é falta de mão de obra qualificada para a produção (BARROSO et al., 2007).

Observando a necessidade de expansão da carcinicultura, a necessidade de capacitação prática dos novos profissionais e o potencial de produção de camarões que a região Oeste do Paraná possui, em 2010, o Laboratório de Carcinicultura da Universidade Federal do Paraná - Setor Palotina (UFPR), deu início projeto de extensão "Desenvolvimento da Carcinicultura no município de Palotina" o qual, com a expansão para outros municípios da região foi renomeado para "Carcinicultura no oeste do Paraná". Estes projetos foram submetidos aos editais PROEXT do MEC, obtendo aprovação nos anos de 2010, 2011, 2013, 2014 e 2015, o que vem garantindo a continuidade das ações e 0 avanço dos resultados junto aos produtores da região.

As principais ações do projeto envolvem o repasse de tecnologia através de cursos de extensão, palestras e distribuição de material didático e 0 acompanhamento da produção junto aos produtores que se integraram ao projeto. Os sistemas de cultivo desenvolvidos são realizados principalmente em policultivo com tilápias, o principal organismo produzido e comercializado na região e também em sistemas de monocultivo onde apenas os camarões são criados nos viveiros. Desta forma, o relato de experiências tem por objetivo estimular a produção aquícola através das atividades realizadas pelo Laboratório de Carcinicultura. Tal iniciativa tem contribuído com a formação de recursos humanos qualificados, bem como, subsidiado a produção por parte de aquicultores, por meio da capacitação e da realização de atividades de extensão.

\section{Relato de experiência na academia}

Até recentemente a formação profissional oferecida por Instituições Federais de Ensino, baseavam-se em um saber pragmático e utilitarista, a partir do qual o profissional era preparado apenas para reproduzir as práticas determinadas pelo modelo vigente (LEITE et al., 2011). Martins (2000) denominou esta formação com base no "fazer sem saber". A formação técnica nesse sistema fomentava a reflexão (para a transformação da sociedade), mas não a criatividade (para a reelaboração e criação de novos métodos).

Portanto, ao observar a necessidade de aplicar o verdadeiro papel da educação profissional, integrando o conhecimento produzido com as carências e necessidades da sociedade, é que serviu como encadeado da integração sociedade com a Universidade, por meio, da troca de conhecimento entre os alunos, professores e produtores. Portanto, os futuros profissionais formados nesse sistema de educação, terão no exercício da cidadania, na conscientização, no desenvolvimento autossustentável da atividade, a habilidade de se relacionar com as mais diferentes pessoas e a experiência prática em seu currículo.

Para construção desse profissional e sistematização da experiência. 0 projeto seleciona todo ano bolsistas dos cursos de engenharia em aquicultura, engenharia em agronomia, ciências 
biológicas, veterinária e tecnologia em biotecnologia da UFPR. Os selecionados são então preparados a atuar com produtores (Fig. 1), na atividade da carcinicultura, por meio de reuniões e palestras. Também são estimulados a participar em trabalhos experimentais que fazem parte de projetos de iniciação científica, mestrado e doutorado, e na participação de eventos técnicos científicos.

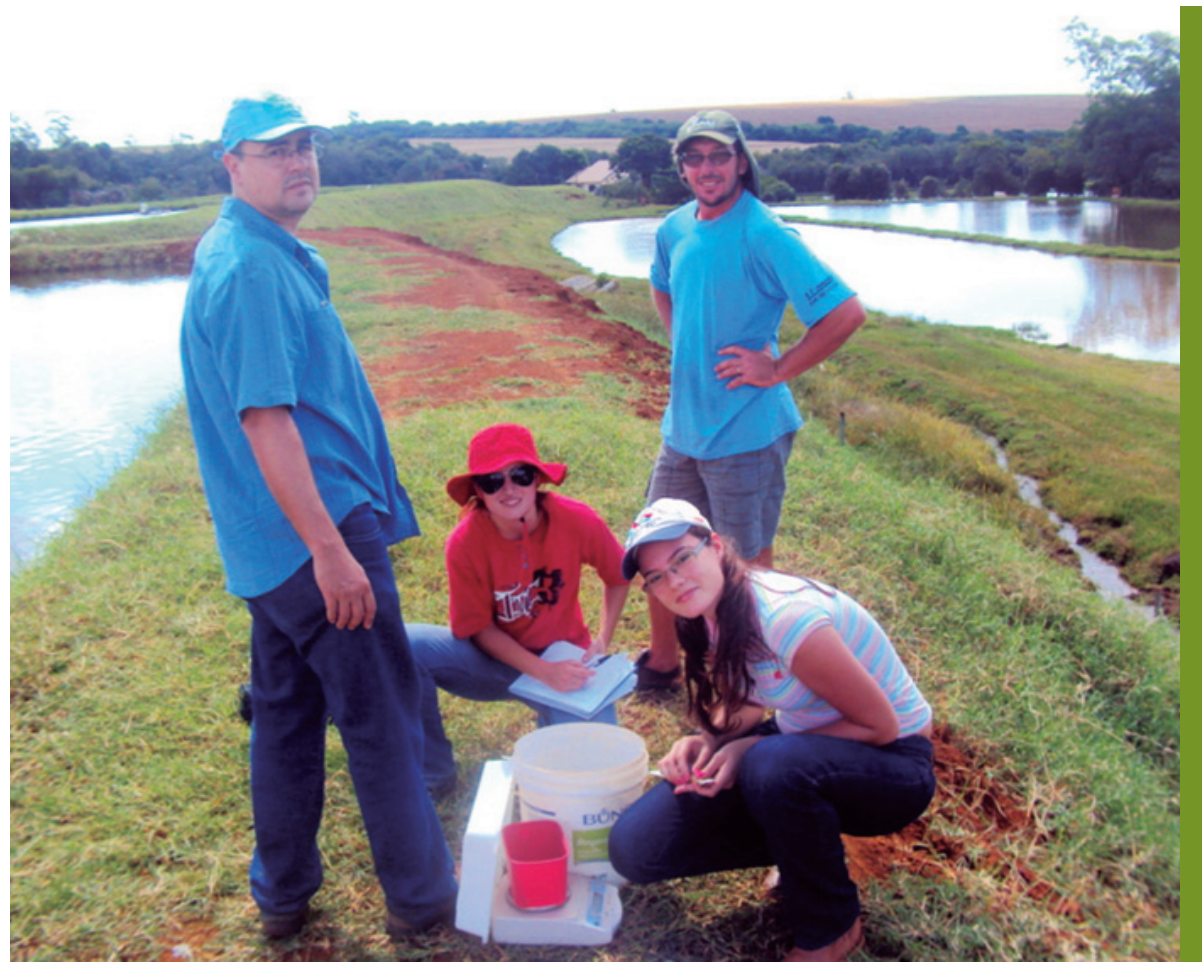

Figura 1: Alunos da Universidade Federal do Paraná, integrante do Laboratório de Carcinicultura prestando assistência técnica.

Ao serem indagados, os bolsistas revelaram os benefícios do projeto para sua formação, onde relataram que: [...] o conhecimento ajudou e complementou 0 entendimento em algumas disciplinas do meu curso. [...] graças ao contato proporcionado pela interação com produtores, adquiri desenvoltura com público. [...] levando conhecimento adquirido na academia até 0 produtor, e auxiliando-os sempre que necessário. Esses relatos respaldam, os beneficio dos trabalhos de extensão, onde, há a inserção dos futuros profissionais com a realidade a ser vivenciada no futuro, possibilitando o aprimoramento de algumas habilidades.

\section{Relato de experiência no setor produtivo}

0 projeto vem apresentando bom impacto econômico e social ao proporcionar o desenvolvimento de uma nova atividade, que pode ser tanto desenvolvida em policultivo, juntamente com a produção de peixes, o que é uma realidade na região, como em monocultivo, produção somente de camarões. Desta forma, os produtores envolvidos podem desenvolver uma atividade complementar a piscicultura, gerando benefícios econômicos e ambientais para a atividade. Ainda sobre os policultivos, a FAO (2009) reforça a importância deste tipo de produção, integrando espécies de diferentes níveis tróficos/nutricionais em um mesmo sistema e aproveitando melhor nutrientes sólidos e solúveis que são transformados em biomassa de organismos produzidos, desta forma, reduz os riscos de eutrofização, promovendo a sustentabilidade econômica e ambiental. Estudos experimentais conduzidos por Santos e Valenti (2002) seguidos por validação em nível comercial demonstraram a viabilidade técnica da produção comercial do policultivo de tilápia do Nilo com camarão de água doce (Fig. 2). Em viveiros povoados com 2 a 4 PLs/m² e 1 a 2 juvenis revertidos para macho de Oreochromis niloticus $/ \mathrm{m}^{2}$ foi obtida uma produção de tilápias equivalente ao obtido no monocultivo, com uma produção adicional de 400 a $800 \mathrm{Kg}$ de camarões com peso médio de 20 a 35 g. A Taxa Interna de Retorno (TIR) pode variar de 15 a $45 \%$ enquanto que o Período de Retorno de Capital (PRN) pode variar de 2,5 a 6 anos. 


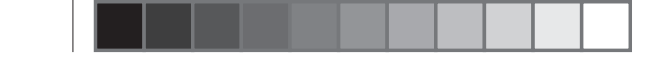

Figura 2: Alunos da

Universidade Federal do

Paraná, integrante do

Laboratório de Carcinicultura

auxiliando na despesca de

um sistema de produção em

policultivo.

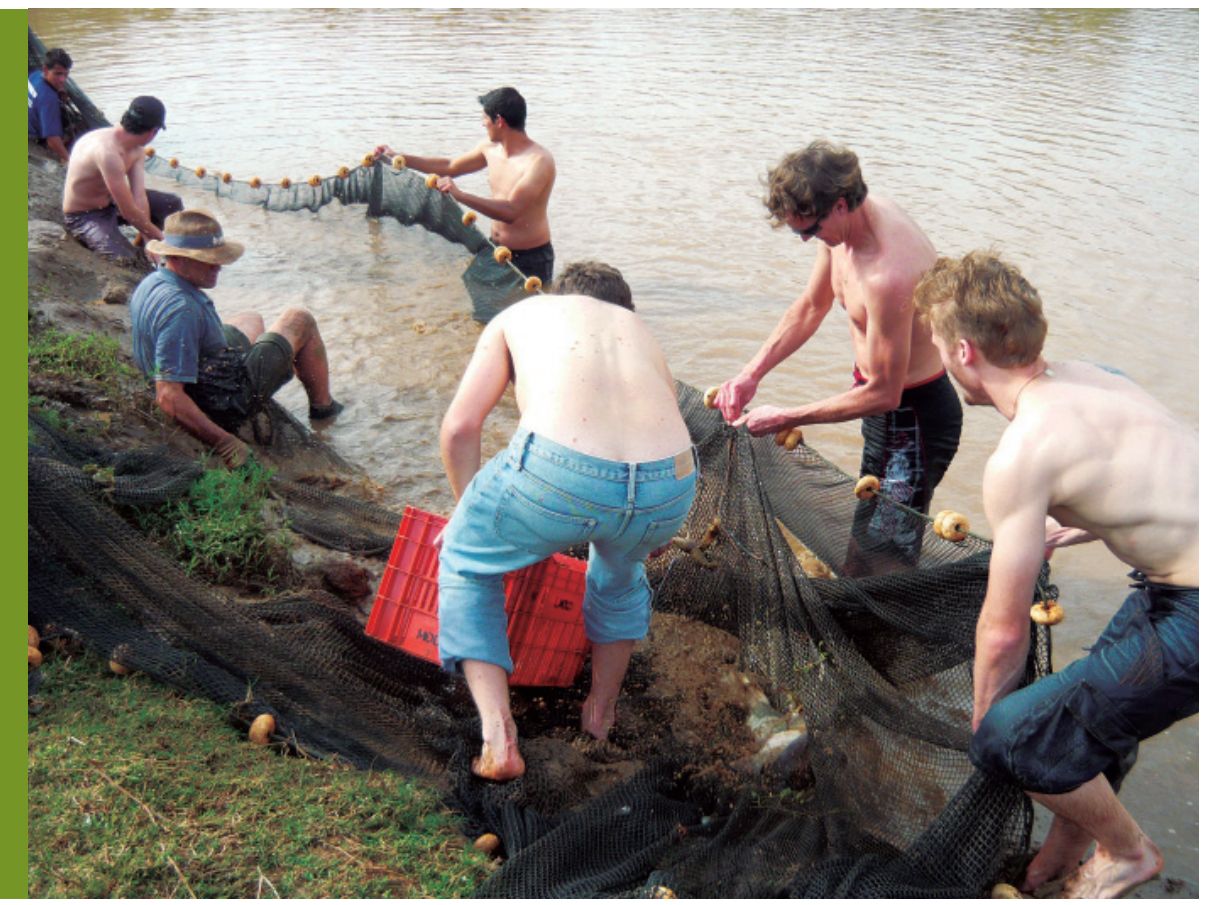

Os produtores interessados na atividade da carcinicultura passam por uma seleção para verificar o perfil. A seleção leva em conta a adequação da propriedade, inclusive em termos de liberação ambiental.

0 Laboratório de Carcinicultura fornece em contrapartida, o auxílio na obtenção das póslarvas (Macrobrachium rosembergii) (Fig. 3), acompanhamento da produção com alunos e professores, a estocagem dos animais nas unidades produtivas, monitorando da qualidade de água e alimentação, análise do crescimento através de biometrias e participação na despesca e abate. No projeto, a cada ano é ofertado aos produtores, profissionais do setor e alunos, 0 curso de capacitação na atividade, com fornecimento de material didático (Cartilha) e palestras, ministrado por professores e alunos da UFPR. 0 curso abrange a parte teórica, apresentando as técnicas utilizadas para produção de PLs e prática no manejo de engorda de camarões, com acompanhamento da produção em unidades produtivas do município.

Figura 3: Produtores recebendo pós-larvas de Macrobrachium rosenbergii.

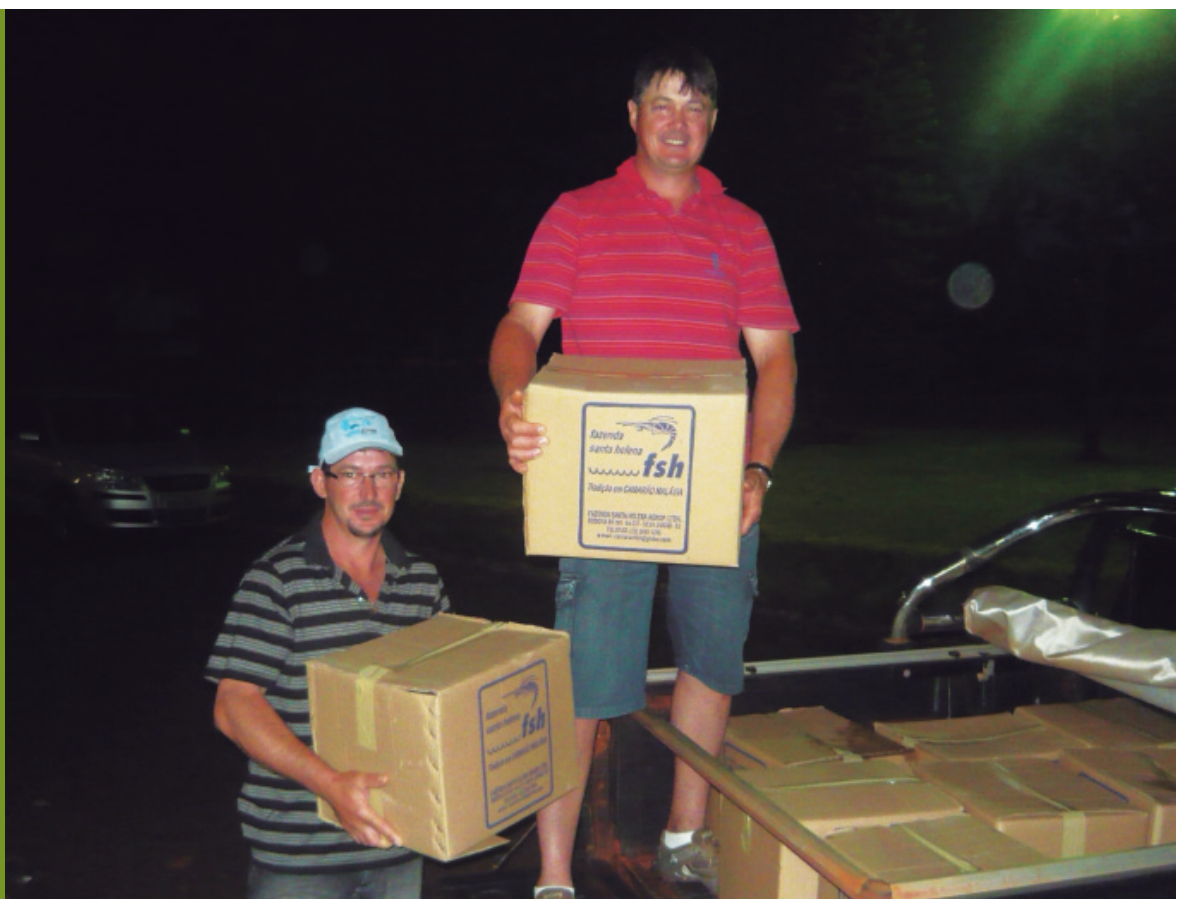


Os resultados obtidos no ultimo ciclo de produção em monocultivo foram de $212 \mathrm{~kg} / 1.000 \mathrm{~m}^{2}$, equivalente a 2,12 ton/há, onde, foi empregada a tecnologia de berçários e substrato artificiais para melhor aproveitamento dos espaços pelos animais. No mesmo ciclo foram realizados policultivo utilizando 11 pós-larvas/m² de camarão e 2 alevinos $/ \mathrm{m}^{2}$ de Tilápia invertido, obtendo ao final da criação em um viveiro de $6.000 \mathrm{~m}^{2}$ uma produção de 5,7 ton/tilápias com peso média de 502 gramas e $450 \mathrm{~kg}$ de camarões com média de 20 gramas. Tais resultados têm deixado os produtores envolvidos satisfeitos, despertado interesse em muitos outros produtores, que procuram a UFPR e o Laboratório em busca de conhecer e participar dos cursos para em seguida possivelmente praticar a atividade de produção de camarão.

Quando questionados sobre como ficou sabendo do projeto; os produtores responderam: [...] Fui apresentado pelo técnico da universidade "Ademir Heldt". [...] Através da associação de aquicultores. Ao serem indagados sobre o que motivou a participar do projeto; os produtores disseram: [...] Possibilidade de criar camarões longe do habitat natural, com custos acessíveis e melhoria na renda. Proporcionando assim, melhor qualidade de vida. [...] Devido o filho estar fazendo um curso a fim (Tecnólogia em Aquicultura), o apoio da universidade e a busca de novas fontes de renda. Na pergunta em que o projeto vem ajudando; foi relatado que: [...] 0 projeto trouxe novos horizontes no cultivo consorciado com tilápia e camarão. [...] Na abertura de novas possibilidades de produção, podendo futuramente possibilitar grandes ganhos financeiros.

Em seu tempo de vida, o projeto já atendeu em seu total 15 produtores, sendo, atualmente atendidos seis produtores, entre os municípios de Palotina, Santa Rosa, Fascismo Alves, Brasilândia do Sul e Marechal Cândido Rondon.

De modo geral, tem sido produzida cerca de uma tonelada de camarões de água doce $(M$. rosembergii) anualmente, além, do desenvolvimento de pesquisas com a espécie $M$. rosembergii e Macrobrachium amazonicum. Além disso, a participação de profissionais do setor produtivo e técnico tem proporcionado uma valiosa troca de informações e experiências, reforçando a importância da atividade extensionista como forma de disseminação e promoção do conhecimento.

\section{Referências}

BARROSO, Gilberto Fonseca; POERSCH, Luís Henrique da Silva; CAVALLI, Ronaldo Olivera. Sistema de cultivos aquícolas na zona costeira do Brasil: recursos, tecnologias, aspectos ambientais e socioeconômicos. Rio de Janeiro: Museu Nacional. 2007.

FAO - Food and Agriculture Organization of the United Nations. The state of world fisheries and aquaculture 2008. Roma: FAO Fisheries and Aquaculture Department, 2009. 176 p.

FAO - Food and agriculture organization of the United Nations. The State of World Fisheries and Aquaculture 2008. Rome: FAO Fisheries and Aquaculture Department, 2012. Disponível em: <http://www.fao.org>. Acesso em: 22 março de 2015.

FAO-Food and Agriculture Organization of the United Nations. The State of world fisheries and aquaculture. Rome: FAO Fisheries and Aquaculture Department, 2014. Disponível em: $<$ <ttp://www.fao.org/3/a-i3720e.pdf>. Acesso em: 22 março de 2015.

LEITE, T.S.; VIEIRA, L.R.; NASCIMENTO, W.L.N.; BENJAMIN, A.M.S.; MELO, A.T.M. Contextualização da experiência: estágio de vivência na comunidade do Jauíra em Concórdia do Pará. Cadernos de Agroecologia, v. 6, n. 2, 1-4, 2011.

MARTINS, Marcos Francisco. Ensino técnico e globalização: cidadania ou submissão? Campinas, SP: Autores Associados, 2000.

MPA - Ministério da Pesca e Aquicultura. Boletim estatístico da pesca e aquicultura, 2011. Brasília: MPA, 2013. 72 p. 
PÉREZ-RAMÍREZ, M.; LLUCH-COTA, S. Fisheries certification in latin America: recent issues and perspectives. Interciência, v. 35, 855-861, 2010.

SANTOS, M.J., VALENTI, W.C. Production of Nile tilapia Oreochromis niloticus and freshwater prawn Macrobrachium rosembergii stocked at different densities in polyculture systems in Brazil. Aquaculture, v.33, n. 3, 369-376, 2002. 